\title{
Echocardiographic features of a mediastinal pancreatic pseudocyst
}

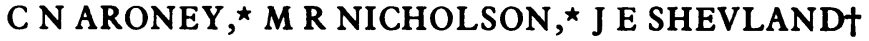 \\ From the ${ }^{\star}$ Cardiology and $\nmid$ Radiology Departments, Royal Hobart Hospital, Hobart, Australia
}

SUMmaRY Cross sectional echocardiography detected a mediastinal pancreatic pseudocyst which caused extracardiac compression in a 49 year old man. Computed tomography confirmed the presence of a cystic lesion lying behind the heart and extending from the pancreas to above the carina. Surgical decompression resulted in resolution of the clinical and echocardiographic findings.

Causes of posterior mediastinal masses include neurofibroma, neuroblastoma, meningocele, aortic aneurysm, clear water pericardial cysts, and hydatid cysts. The echocardiographic features of cardiac compression due to posterior mediastinal malignant tumours, left atrial wall tumours, ${ }^{1}$ and pericardial effusion $^{2}$ have been reported.

There have been 30 reported cases of mediastinal extension of a pancreatic pseudocyst ${ }^{3-10}$ including one in which the $M$ mode echocardiographic features resembled those of a left atrial myxoma. ${ }^{11}$ Nevertheless, the cross sectional echocardiographic features of cardiac compression by a mediastinal pancreatic pseudocyst have not previously been described.

\section{Case report}

A 49 year old man with a long history of heavy alcohol consumption had a history of progressive dysphagia, persistent vomiting, dull epigastric pain, and severe weight loss. On examination he was thin and cachectic. Abdominal examination showed no abnormality, and there were no signs of chronic liver disease. His heart rate was 80 beats/minute, blood pressure 120/70 $\mathrm{mm} \mathrm{Hg}$, and inspiratory variation within normal limits. The cardiac apex was overactive and displaced to the anterior axillary line in the sixth intercostal space. On auscultation he had a harsh systolic murmur at the left sternal edge which increased with respiration and decreased on standing. His carotid upstroke was normal. Serum amylase activity was $\mathbf{2 5 0}$ IU/L (normal $<150 \mathrm{IU} / \mathrm{L}$ ). Liver function tests were normal, as was the full blood count. Abdominal $x$ ray

Requests for reprints to Dr M R Nicholson, Department of Cardiology, Royal Hobart Hospital, Hobart 7000, Tasmania, Australia. films showed pancreatic calcification and a chest $x$-ray film a small left pleural effusion. The electrocardiogram showed increased QRS amplitude over the precordial leads and lateral $T$ wave inversion. Gastroscopy indicated anterior compression of the oesophagus by a pulsatile mass $5 \mathrm{~cm}$ below the level of the cricopharyngeal junction.

Cross sectional echocardiography showed a $10 \mathrm{~cm}$ diameter cystic lesion posterior to the heart and outside the pericardium. In the long axis view the cyst compressed the left atrium and left ventricle (Fig. 1), with the left ventricular end diastolic diameter being $2.0 \mathrm{~cm}$ (normal $>3.5 \mathrm{~cm}$ ) and the left atrial diameter $1.7 \mathrm{~cm}$ (normal $>1.9 \mathrm{~cm}$ ). In the short axis view there was compression of the left and right ventricles and the heart was displaced anteriorly. The cyst extended caudally below the cardiac apex and cranially behind the left atrium. On standing the diameter of the cyst decreased to $8 \mathrm{~cm}$. The heart valves and chambers were otherwise normal.

Computed tomography showed a cystic lesion in the posterior mediastinum extending from the pancreas to above the carina (Fig. 2).

At laparotomy a pancreatic cyst communicating with the mediastinum along the psoas muscle beneath the medial arcuate ligament was found and treated by internal drainage. The amylase content of the fluid was $3500 \mathrm{IU} / \mathrm{L}$.

Postoperatively the patient's clinical state rapidly improved. The systolic murmur disappeared as did the abnormal clinical and electrocardiographic findings. Repeat cross sectional echocardiography two months later showed that the diameter of the cyst had decreased from $10 \mathrm{~cm}$ to $3.5 \mathrm{~cm}$. The features of cardiac compression had resolved; notably, the left ventricular end diastolic diameter had increased from 

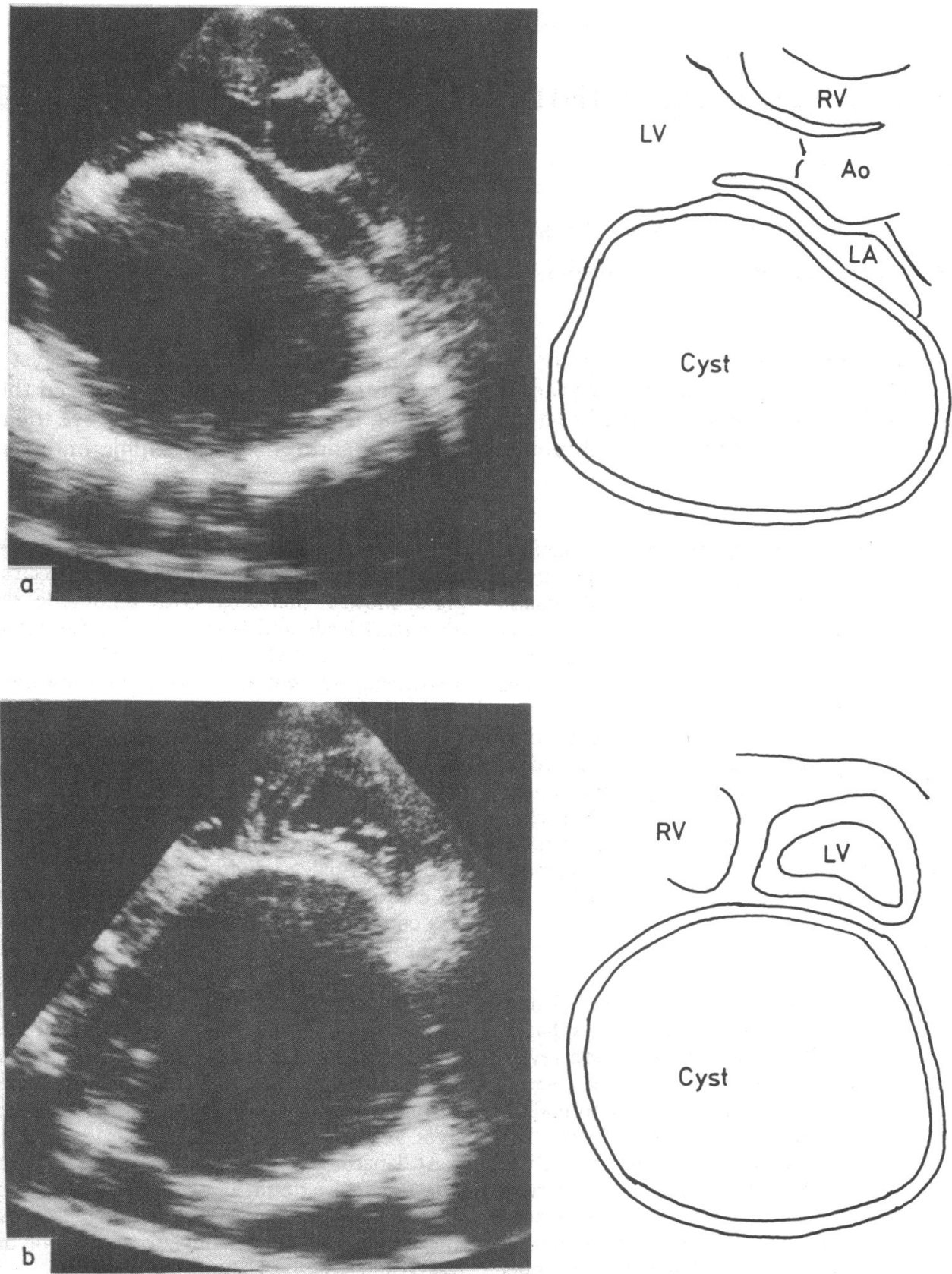

Fig. 1 Cross sectional echocardiograms in (a) the long and (b) the short axis parasternal views showing a $10 \mathrm{~cm}$ diameter cystic lesion posterior to the heart compressing the lefi atrium $(L A)$ and left ventricle $(L V)$. Ao, aorta; $R V$, right ventricle. 

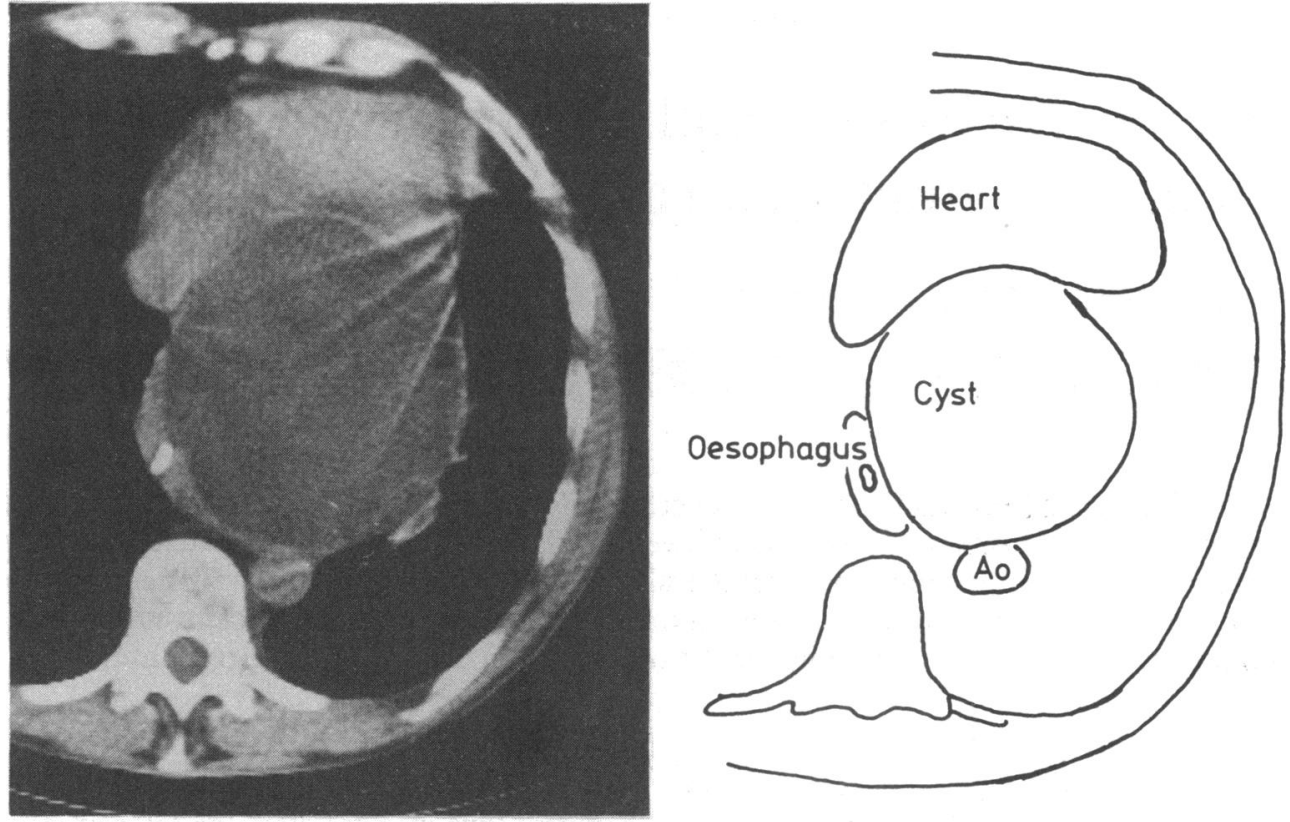

Fig. 2 Computed tomogram of the thorax showing a large cystic mass posterior to and compressing the heart. The oesophagus is also compressed, and there is a nasogastric tube in position.

$2.0 \mathrm{~cm}$ to $3.5 \mathrm{~cm}$ and the left atrial diameter from 1.7 $\mathrm{cm}$ to $2.7 \mathrm{~cm}$.

\section{Discussion}

Weidmann et al reported a patient with a mediastinal pancreatic pseudocyst who, before this diagnosis had been made, underwent cardiac catheterisation because of a prominent systolic murmur. ${ }^{12}$ Angiography showed pronounced compression of the left atrium and ventricle, and there was a distinct systolic pressure gradient between the inflow and outflow tracts of the right ventricle. These findings correlate closely with those in our case and suggest that the systolic murmur was due to an infundibular pressure gradient in the right ventricle. The pronounced precordial impulse and electrocardiographic features suggesting left ventricular hypertrophy were probably due to anterior displacement of the heart.

The presence of the clinical features of cardiac compression or evidence of a cystic lesion of the posterior mediastinum in patients with chronic alcoholism, pancreatitis, or a pancreatic pseudocyst should raise the possibility of a mediastinal extension of a pseudocyst.

\section{References}

1 Yoshikawa J, Sabah I, Yanagihara K, Owaki T, Kato H, Tanemoto K. Cross-sectional echocardiographic diagnosis of large left atrial tumor and extracardiac tumor compressing the left atrium. Am $\mathcal{F}$ Cardiol 1975; 42: 853-7.

2 Vignola PA, Pohost GM, Curfman GD, Myers GS. Correlation of echocardiographic and clinical findings in patients with pericardial effusion. Am $\mathcal{F}$ Cardiol 1976; 37: 701-7.

3 Jaffe BM, Ferguson TB, Holtz S, Shields JB. Mediastinal pancreatic pseudocysts. Am f Surg 1972; 124: 600-6.

4 Spina GP, Maruotti RA, Montorsi M, Viani MP, Galeotti F. Faux kystes du pancreas à extension médiastinale. A propos de deux cas. Ann Chir 1983; 37: 222-4.

5 Rodan BA, Gocke TM, Bean WJ, Feng TS. Mediastinal pancreatic pseudocyst. South Med f 1983; 76: 262-3.

6 McCarthy S, Bookbinder M, Blumenfeld J, Kelly LJ, Keohane MF. Mediastinal pseudocyst. $\mathcal{f}$ Clin Gastroenterol 1982; 4: 45-8.

7 Milleret P, Weill F, Bassand JP, et al. Pseudokyste pancréatique géant à dévelopement rétropéritonéal et à extension médiastinale et intrapsoïque. Chirurgie 1982; 108: 492-5.

8 Tada S. Pancreatic pseudocyst extending from the mediastinum to the psoas muscle. Rinsho Hoshasen 1981; 26: 809-10.

9 Ball JB, Clark RA. CT of mediastinal pancreatic fluid collections. Comput Radiol 1982; 6: 295-300.

10 Siegelman SS, Copeland BE, Saba GP, Cameron JL, Sanders RC, Zerhouni EA. CT of fluid collections associated with pancreatitis. AFR 1980; 134: 1121-32.

11 Shah A, Schwartz H. Echocardiographic features of cardiac compression by mediastinal pancreatic pseudocyst. Chest 1980; 77: 440-3.

12 Weidmann P, Rutishauser W, Siegenthaler W, Senning A. Mediastinal pseudocyst of the pancreas. Am $\mathcal{J}$ Med 1969; 46: 454-9. 